\title{
Desafios teórico-metodológicos para a interpretação da migração internacional na sociedade contemporânea
}

\author{
Rosana Baeninger ${ }^{\star}$
}

\begin{abstract}
CANALES, Alejandro. E pur si muove - Elementos para una teoria de las migraciones en el capitalismo global. Guadalajara, México: Universidad de Guadalajara, MAPorruá Editor, 2015.
\end{abstract}

0 contexto atual das migrações internacionais impõe desafios teórico-conceituais para a compreensão da era da migração (CASTLES; MILER, 2004). 0 estudo publicado pelo professor Canales reflete parte importante desses desafios, em especial - e talvez 0 mais importante -, com o olhar latino-americano para as questões migratórias. 0 livro é composto por seis capítulos, além da introdução e conclusão.

Conhecer a obra é um rico exercício de revisão bibliográfica em diálogo com o argumento principal do livro: "como esa autoreproducción de la migración forma parte significativa de los processos de reproducción de la sociedade en su conjunto" (CANALES, 2015, p. 33). Partindo do entendimento de comunidades transnacionais, em que origem e destino são partes de um mesmo processo que as articulam, o autor enfatiza a necessidade de um modelo de análise para a migração internacional contemporânea que a considere um componente da estruturação da sociedade nesta era da globalização.

0 capítulo 1 , “Migración y reproducción. Premisas básicas”, aponta que a migração internacional, suas causas e consequências precisam ser analisadas sob a ótica do mundo globalizado, no qual a migração é componente da estruturação dessa sociedade global em sua dinâmica e reprodução. Assim, o capítulo dedica-se à discussão acerca da reprodução da população (LIVI BACCI, 1993), reprodução da migração (DURAND; MASSEY, 2003) e reprodução das sociedades e suas mediações com enfoque em Bourdieu. Para completar tais

\footnotetext{
*Departamento de Demografia, Instituto de Filosofia e Ciências Humanas e Núcleo de Estudos de População “Elza Berquó” (Nepo), Universidade Estadual de Campinas (Unicamp), Campinas-SP, Brasil (baeninger@nepo.unicamp.br).
} 
reflexões, Canales retoma o conceito de causação circular e acumulativa de Myrdal (1957), com análises dos processos de reprodução das estruturas de desigualdades presentes na sociedade, para entender a migração internacional como componente da reprodução do sistema mundo.

Com base nas interpretações da sociedade receptora e de organismos internacionais, o autor constrói, no capítulo 2 - "Migración y desarrollo. Tres tesis y um corolario" - uma posição crítica sobre a visão hegemônica da relação migração e desenvolvimento. Ele argumenta que as "consecuencias y efectos de la migración sobre el desarrollo, no son independientes de las causas estructurales que desde el desarrollo impulsan la migración" (CANALES, 2015, p. 55). As teses formuladas correspondem ao entendimento da migração e desenvolvimento em uma perspectiva global, à relação entre etapa de desenvolvimento e sistema migratório e às causas da migração como reflexos do modelo de desenvolvimento e da integração da economia global. 0 corolário, a partir destas três teses, é que o modelo migratório da era global participa da reprodução da sociedade como reprodução demográfica, como reprodução da economia e do capital, como reprodução da estratificação e das desigualdades sociais.

No capítulo 3, "Migración y reproducción. Más allá de la crítica al nacionalismo metodológico", é realizada a discussão acerca dos limites do Estado-nação na configuração e problematização da migração internacional. As categorias nacionais já não são capazes de responder à complexidade do fenômeno migratório que se expressa em âmbito local, mas refletem processos globais. A globalização traz um contexto de desterritorialização da vida social, configurando comunidades transnacionais. "La migración ya no implica necessariamente una ruptura con el origen, comunidade y la familia. Por el contrario, passa a ser una forma de ampliar y extender las relaciones familiares y comunitárias" (CANALES, 2015, p. 72). Assim, a questão da assimilação é discutida, apontando a obsolescência de conceitos e teorias para explicar a migração internacional. A relação migração e reprodução faz sentido no entendimento da reprodução e transformação da sociedade em seu conjunto, "en la reproducción de las estructuras de desigualdade y diferenciación social que caracterizan a la globalización” (CANALES, 2015, p. 79).

Os capítulos seguintes se estruturam a partir do papel da migração na reprodução da sociedade e sua função: na reprodução da população, na reprodução do capital e na reprodução social (estrutura de classes e desigualdade social).

A transição demográfica e migração é discutida no capítulo 4, "El papel de la migración en el sistema global de reproducción demográfica”. É enfatizada a importância da contribuição da migração internacional como parte intrínseca do sistema de reprodução de população de muitos países. Analisam-se o envelhecimento da população, o bônus demográfico nos países de origem, a primeira transição demográfica, a segunda transição demográfica e os dilemas e contradições da importância da migração internacional para a reprodução da força de trabalho e do crescimento populacional a partir de grupos étnicos específicos nos países receptores. 
O capítulo 5, "Migración y reproducción del capital”, aborda as enormes transferências de força de trabalho para os países de destino geradas pela migração internacional e seu caráter laboral, sendo que os países de origem contam com as remessas monetárias dessa emigração. Apontam-se, ainda, a importância das redes sociais e o fluxo de remessas para o sustento da reprodução dos migrantes e de suas famílias, no âmbito de um sistema global de reprodução da economia, com a mobilidade da força de trabalho e sua reprodução a partir da inserção em ocupações flexíveis, instáveis e precárias. Para Canales (2015, p. 136),

[...] en este sentido, planteamos una situación paradójica en relación con la migración y globalización. Como hemos señalado en capítulos anteriores, aunque los migrantes casi nunca aparecen como uno de los actores que concentre los reflectores de la globalización, su trabajo sí forma parte directa de la globalización del capital, en la medida que constituye, como hemos visto, un elemento sustancial sin el cual la misma dinâmica económica de los países desarrollados se vería seriamente mermada. Como trabajo, los migrantes participan diretamente de la globalización y contribuyen a la reproducción y acumulación del capital a escala global.

A relevância da migração como um sistema global translocal e transnacional de reprodução social é discutida no último capítulo, “Migración y reproducción”. "En efecto, la migración permite articular el processo de reproducción social de la población nativa en los lugares de destino con la reproducción social de la población en los lugares y comunidades de origen" (CANALES, 2015, p. 154). 0 autor acrescenta que tais articulações ocorrem como mecanismos de reprodução de diferentes classes sociais, por meio de um sistema de classes global e transnacionalizado. As redes sociais e as remessas produzem, de um lado, um sujeito migrante específico - "al trabajador cuyo trabajo consiste precisamente dar sustento a la reproducción social de clases sociales medias y altas en los países de destino" (CANALES, 2015, p. 155) - e, de outro, a reprodução das famílias na origem. Assim, a reprodução social passa também a ser globalizada, com a migração internacional produzindo a intersecção entre os processos locais de reprodução social, interconectando a reprodução social de uns e outros no contexto global das desigualdades sociais.

Nesse sentido, as reflexões presentes no livro remetem-nos a um novo olhar sobre os processos migratórios atuais na América Latina. A perspectiva da reprodução global e transnacionalizada da migração laboral implica entender que as migrações entre países limítrofes não se limitam apenas às migrações de vizinhança ou de fronteira, mas revelam também a reprodução e acumulação do capital em escala global.

A obra avança na compreensão de imigrantes transnacionais, em suas práticas sociais que atravessam o Estado-Nação e em seus espaços de vida (DOMENACH; PICOUET, 1990). $O$ autor discute com brilhantismo os limites de categorias e conceitos pertencentes a outros momentos da sociedade e reflete a interdisciplinaridade inerente ao tema da migração internacional. 0 livro constitui, portanto, leitura obrigatória para os estudiosos da era da migração. 


\section{Referências}

BOURDIEU, P. Las estratégias de la reproducción social. Buenos Aires: Siglo XXI Editores, 2011. CASTLES, S.; MILLER, M. La era de la migracion: movimientos internacionales de población en el mundo moderno. México: Cámara de Diputados LIX Legislatura, UAZ, Secretaría de Gobernación, Instituto Nacional de Migración, Fundación Colosio, Miguel Ángel Porrua, 2004.

DOMENACH, H.; PICOUET, M. El caracter de reversibilidad en el estudio de la migracion. Notas de población, n. 49, p. 49-68, 1990.

DURAND, J.; MASSEY, D. Clandestinos. Migración México-Estados Unidos em los albores del siglo XXI. México: Miguel Ángel Porruá/Universidade Autónoma de Zacatecas, 2003.

LIVI BACCI, M. Notas sobre la transición demográfica em Europa y América Latina. In: IV CONFERENCIA LATINOAMERICANA DE POBLACIÓN. Actas... México: Abep/Celade, lussp, Prolap, Somede, 1993.

MYRDAL, G. Teoría económica y regiones subdesarrolladas. México: Fondo de Cultura Económica, 1979 [1957].

\section{Sobre a autora}

Rosana Baeninger é doutora em Ciências Sociais. Professora Livre-Docente do Departamento de Demografia e do Núcleo de Estudos de População “Elza Berquó”, da Universidade Estadual de Campinas (Unicamp).

\section{Endereço para correspondência}

Rua Tingui, 141 - Alphaville

13098-303 - Campinas-SP, Brasil

Recebido para publicação em 30/07/2016

Aceito para publicação em 10/07/2017 